\title{
Acute and Sub-acute Toxicity of Commiphora swynnertonii extracts: an Experimental Study on Albino Mice and Rats
}

\section{Disela Edwin', Paul Erasto², Sylvester Temba', Musa Chacha'* \\ ${ }^{1}$ School of Life Sciences and Bio-Engineering, Nelson Mandela African Institution of Science and Technology, P.O. Box 447, Arusha-Tanzania \\ ${ }^{2}$ National Institute of Medical Research, P.O. Box 9653 Dar es salaam-Tanzania \\ Study Area: Simanjiro district in Arusha region, Tanzania \\ Coordinates: 3"34'S; 3"659'E}

Key words: Hematological, Biochemical, Histology, Body- weight.

\section{Abstract}

The acute and subacute toxicity of Commiphora swynnertonii extracts on albino mice and rats was verified. For the acute toxicity study, oral administration of $C$. swynnertonii hexane and chloroform extract with doses of 500,1000 , and $2000 \mathrm{mg} / \mathrm{kg}$ body weight induced no treatment-related signs of toxicity in the animals during the 14 days of the experimental period. In the sub-acute toxicity, C. swynnertonii hexane extract showed a significant decrease in mean corpuscular volume (MCV), hematocrit (HCT) and a significant increase in Mean platelet volume (MPV). A significant decrease in aspartate aminotransferase (AST) and creatinine was also observed. In the rats treated with $C$. swynnertonii chloroform extract, the significant change in white blood cell (WBC), Red blood cell (RBC), Mean corpuscular volume (MCV), Mean hemoglobin concentration $(\mathrm{MCH})$, Mean platelet volume (MPV) and hemoglobin ( $\mathrm{Hb}$ ) were observed.The significant change in alanine aminotransferase (ALT), aspartate aminotransferase (AST), alkaline phosphate (ALP), creatinine, albumin and bilirubin was also observed.

antifungal and antiviral activity (Mkangara et al., 2014b). This paper reports the acute and subacute toxicity of $C$. swynnertonii hexane and chloroform extracts.

\section{Methodology:}

Exudates collection: exudates of $C$. swynnertonii were collected from Mererani, Simanjiro district in Arusha region, Tanzania. The plant was identif ied by a botanist from TPRI and voucher specimen coded CS oo1 is deposited at the Nelson Mandela African Institution of Science and Technology.

Extraction of plant materials: exudates weighed $78.8 \mathrm{~g}$ was mixed with $150 \mathrm{ml}$ of distilled water followed by $150 \mathrm{ml}$ of hexane. The solution was thoroughly shaken and allowed to settle in order to form two layers. The hexane layer was separated from aqueous layer by decantation. Further, $150 \mathrm{ml}$ of chloroform was poured into the separating funnel containing aqueous layer. The solution was shaken and left for $6 \mathrm{hrs}$ and the chloroform layer was separated from the aqueous layer. The two extracts obtained were concentrated through vacuum rotary evaporator, the extracts obtained were kept in a beaker covered with aluminum foil, stored at $4^{\circ} \mathrm{C}$ for further use.

*Corresponding Author: musa.chacha@nm-aist.ac.tz 
Experimental animals: albino mice of both sexes, weighted between $19-36 \mathrm{~g}$ aged 4 to 5 weeks and albino rats of both sexes weighed between 46-192g aged 7 - 8 weeks were randomly obtained from Sokoine University of Agriculture (SUA), Morogoro, Tanzania. The animals were allowed to stay in cages with sawdust litters at a controlled temperature of about $25^{\circ} \mathrm{C}$ to $29^{\circ} \mathrm{C}$ and lighting of 12 hours of light and 12 hours of darkness for each 24 hours period.

Acute oral toxicity: the toxicity study was done according to Organization for Economic Co-operation and Development (OECD) guidelines number 425 of 2001 (OECD/OCDE, 2001). The mice were acclimatized for 7 days before treatments, and they were provided with standard diet and water. The animals were divided into seven groups of six animals each ( 3 males and 3 females), one control groups and six treated groups. Body weights of the mice were determined and the dose was calculated in accordance with their body weights. The control group was given distilled water and the three treated groups were given doses of 500,1000 and $2000 \mathrm{mg} / \mathrm{kg}$ body weight of hexane extract while other three groups were given doses of 500,1000 and $2000 \mathrm{mg} / \mathrm{kg}$ body weight of chloroform extract. The animals were observed for their toxic symptoms, behavioral changes, and mortality at least once daily for 14 days.

Sub-acute toxicity: forty-two albino rats were divided into seven groups of six animals each ( 3 males and 3 females), one control groups and six treated groups. Control group was given distilled water and the three treated groups were given doses of 250, 500 and 1000 $\mathrm{mg} / \mathrm{kg}$ body weight of hexane extract while other three groups were given doses of 250,500 and $1000 \mathrm{mg} / \mathrm{kg}$ body weight of chloroform extract. All administrations were done every 24 hours via oral gavage throughout the experimental period. The rats were weighed daily and also subjected to thorough observations for mortality and any behavioral changes, during the 28-day experimental period. After 28 days all rats were weighed and the blood of each rat was collected through eye orbital vein into two vacutainer tubes for each animal. Hematological parameters including white blood cell (WBC), Red blood cell (RBC), Hematocrit (HCT), Mean corpuscular volume $(\mathrm{MCV})$, Mean hemoglobin concentration $(\mathrm{MCH})$, Mean platelet volume (MPV), Mean corpuscular hemoglobin concentration $(\mathrm{MCHC})$, and hemoglobin $(\mathrm{Hb})$ were determined using the blood samples contained in the EDTA tubes. The blood samples contained in plain vacutainer tubes were centrifuged and the serum obtained was subjected to biochemical parameters such as total protein, bilirubin, alkaline phosphate (ALP), aspartate aminotransferase (AST), alanine aminotransferase (ALT), creatinine and albumin. After blood collection, all rats were dissected and internal organs such as liver, heart, lungs, spleen, and kidneys were carefully removed and weighed individually. Organs were fixed in $10 \%$ formalin then sections were prepared and stained with hematoxylin and eosin before microscopic examination.

Statistical analysis: the Student's t-test was used to compare initial body weight and final body weight for both control and treated groups of animals while one-way analysis of variance (ANOVA) was used for multiple comparisons of the means for hematological, biochemical and organ weight data between the control and treated groups of animals. All statistical analysis was by STATISTICA software-8; level of signif icance $\mathrm{p}<0.05$.

\section{Results :}

Acute oral toxicity: the oral administration of $C$. swynnertonii hexane and chloroform extract at 500, 1000 and $2000 \mathrm{mg} / \mathrm{kg}$ body weight doses had no clinical adverse effect of substance related toxicity and did not cause any mortality during the 14-days observation period.

Sub-acute toxicity: daily repeated oral administration of C. swynnertonii hexane and chloroform extract at 250, 500 and $1000 \mathrm{mg} / \mathrm{kg}$ body weight doses for 28 days did not induce any evident sign of toxicity and mortality in the treated animals.

Body weight changes: in the $C$. swynnertonii hexane extract the significant increase $(\mathrm{p}<0.05)$ in body weight of male rats was observed in control and at the dose of 250 $\mathrm{mg} / \mathrm{kg}$ body weight (Table-1). In C. swynnertonii chloroform extract the significant increase $(\mathrm{p}<0.05)$ in body weight was observed in control male while at the dose of $500 \mathrm{mg} / \mathrm{kg}$ body weight, the significant increase $(\mathrm{p}<0.05)$ in body weight was observed in both male and female rats (Table-2).

Organ weight: finding from this study revealed that the weight of the liver treated with $C$. swynnertonii hexane extract was significantly decreased $(\mathrm{p}<0.05)$ while the other organs such as heart, spleen, lung and kidney showed no significant change in weight (Table-3). Further the signif icant decrease $(\mathrm{p}<0.05)$ in weight of liver, heart, spleen, lung, and kidney were observed in the rats treated with C. swynnertonii chloroform extract (Table-4).

Hematological parameters: finding from this study revealed that, with the exception of significant decrease $(\mathrm{p}<0.05)$ in MCV, HCT and signif icant increase $(\mathrm{p}<0.05)$ in MPV in the rats treated with $C$. swynnertonii hexane extract, administration of this extract at all the investigated doses had no significant ( $p>0.05$ ) effect on $\mathrm{WBC}, \mathrm{RBC}, \mathrm{MCH}, \mathrm{MCHC}$ and $\mathrm{Hb}$ when compared with control (Table-5). Additionally the significant decrease $(\mathrm{p}<0.05)$ in $\mathrm{WBC}, \mathrm{RBC}, \mathrm{MCV}, \mathrm{MCH}, \mathrm{Hb}$ and significant increase $(\mathrm{p}<0.05)$ in MPV was observed in the rats treated with C. swynnertonii chloroform extract (Table-6). 
Biochemical parameters: significant decrease $(\mathrm{p}<0.05)$ in ALP level was observed in male rats whereas significant decreased in AST and creatinine was observed in the female rats treated with $C$. swynnertonii hexane extract (Table-7). Furthermore signif icant increase $(\mathrm{p}<0.05)$ in ALT, AST and creatinine observed in rats treated with $C$. swynnertonii chloroform extract while significant decrease $(\mathrm{p}<0.05)$ in albumin and significant increase $(\mathrm{p}<0.05)$ in bilirubin was observed in the male rats treated with $C$. swynnertonii chloroform extract (Table-8).

Histopathological analysis: the microscopic examinations of the liver, kidney, spleen, lung, and heart of the animals treated with $C$. swynnertonii hexane extract revealed no abnormalities in the overall structural orientation of the organs during subacute toxicity study (Fig.1). Furthermore, the examination of a liver section of the animals treated with $C$. swynnertonii chloroform extract revealed moderate to severe congestion and the initial stage of necrosis (Fig.2). The kidney section of the animals treated with C. swynnertonii chloroform extract induced congestion and destruction in the glomerulus's shape (Fig.-2).

Table-1: Body weight (g) of control \& rats treated with C. swynnertonii hexane extract measured during subacute toxicity

\begin{tabular}{lllll}
\hline $\begin{array}{l}\text { Dose } \\
(\mathrm{mg} / \mathrm{kg} \text { BW })\end{array}$ & Sex & $\begin{array}{l}\text { Mean } \pm \text { SEM } \\
\text { at day o }\end{array}$ & $\begin{array}{l}\text { Mean } \pm \text { SEM } \\
\text { at day } 28\end{array}$ & P-value \\
\hline Control & M & $80 \pm 3.00$ & $123 \pm 8.00$ & 0.04 \\
& F & $107 \pm 13.00$ & $117.5 \pm 20.5$ & 0.70 \\
250 & M & $68 \pm 5.00$ & $104.5 \pm 5.5$ & 0.04 \\
& F & $58.5 \pm 12.5$ & $82 \pm 12.00$ & 0.31 \\
500 & M & $87.5 \pm 26.5$ & $96.5 \pm 30.5$ & 0.84 \\
& F & $58 \pm 2.00$ & $77.5 \pm 7.5$ & 0.13 \\
1000 & M & $154.5 \pm 37.5$ & $192.5 \pm 15.5$ & 0.45 \\
& F & $115 \pm 23.00$ & $121 \pm 21.00$ & 0.86 \\
\hline
\end{tabular}

Table-2: Body weight (g) of control and rats treated with $C$. swynnertonii chloroform extract measured during sub-acute toxicity

\begin{tabular}{lllll}
\hline $\begin{array}{l}\text { Dose } \\
(\mathrm{mg} / \mathrm{kg} \mathrm{BW})\end{array}$ & $\begin{array}{l}\text { Sex } \\
\text { Control }\end{array}$ & $\begin{array}{l}\text { Mean } \pm \text { SEM } \\
\text { at day o }\end{array}$ & $\begin{array}{l}\text { Mean } \pm \text { SEM } \\
\text { at day } 28\end{array}$ & P-value \\
& F & $107 \pm 13.00$ & $123 \pm 8$ & 0.04 \\
250 & M & $72 \pm 7.00$ & $96 \pm 20.00$ & 0.37 \\
& F & $67 \pm 8.00$ & $79.5 \pm 0.5$ & 0.26 \\
500 & M & $77.5 \pm 1.5$ & $104.5 \pm 2.5$ & 0.01 \\
& F & $63 \pm 0.00$ & $90.5 \pm 3.5$ & 0.01 \\
1000 & M & $116.5 \pm 12.5$ & $131 \pm 10.00$ & 0.46 \\
& F & $121.5 \pm 21.5$ & $143.5 \pm 20.5$ & 0.54 \\
\hline
\end{tabular}

$\mathrm{M}=$ male, $\mathrm{F}=$ female, $\mathrm{BW}=$ body weight
Table- 3 to 8: Different superscripts denote statistical significance as per Duncan's multiple range test $(\mathrm{p}<0.05)$

Table-3: Organ-body weight of control \& rats treated with $C$. swynnertonii hexane extract measured during sub-acute toxicity.

\begin{tabular}{lllllll}
\hline Organ & Sex & Control & $250^{*}$ & $500^{*}$ & $1000^{*}$ & P-value \\
\hline Liver & M & $3.50 \pm 0.11^{\mathrm{a}}$ & $2.42 \pm 0.28^{\mathrm{b}}$ & $3.47 \pm 0.60^{\mathrm{a}}$ & $3.16 \pm 0.28 \mathrm{a}$ & 0.02 \\
& $\mathrm{~F}$ & $4.16 \pm 0.48^{\mathrm{a}}$ & $4.41 \pm 0.48^{\mathrm{a}}$ & $3.65 \pm 0.01^{\mathrm{a}}$ & $1.98 \pm 0.22^{\mathrm{b}}$ & 0.03 \\
Heart & $\mathrm{M}$ & $0.59 \pm 0.04$ & $0.44 \pm 0.02$ & $0.63 \pm 0.05$ & $0.45 \pm 0.03$ & 0.06 \\
& $\mathrm{~F}$ & $0.59 \pm 0.02$ & $0.58 \pm 0.11$ & $0.43 \pm 0.06$ & $0.38 \pm 0.10$ & 0.3 \\
Spleen & $\mathrm{M}$ & $0.25 \pm 0.02$ & $0.21 \pm 0.01$ & $0.39 \pm 0.05$ & $0.22 \pm 0.03$ & 0.06 \\
& $\mathrm{~F}$ & $0.32 \pm 0.02$ & $0.27 \pm 0.04$ & $0.26 \pm 0.00$ & $0.20 \pm 0.05$ & 0.22 \\
Lungs & $\mathrm{M}$ & $0.78 \pm 0.18$ & $0.58 \pm 0.03$ & $1.18 \pm 0.24$ & $0.69 \pm 0.14$ & 0.20 \\
& $\mathrm{~F}$ & $1.06 \pm 0.25$ & $1.09 \pm 0.24$ & $0.74 \pm 0.12$ & $0.44 \pm 0.14$ & 0.12 \\
Kidney & $\mathrm{M}$ & $0.49 \pm 0.16$ & $0.32 \pm 0.02$ & $0.84 \pm 0.16$ & $0.33 \pm 0.02$ & 0.09 \\
& $\mathrm{~F}$ & $0.48 \pm 0.01$ & $0.49 \pm 0.11$ & $0.43 \pm 0.03$ & $0.29 \pm 0.05$ & 0.09 \\
\hline
\end{tabular}

Values: mean \pm SEM, M=Male, F=Female, ${ }^{*} \mathrm{mg} / \mathrm{kg}$ BW

Table-4: Organ-body weight of control and rats treated with $C$. swynnertonii chloroform extract measured during sub-acute toxicity

\begin{tabular}{lllllll}
\hline Organ & Sex & Control & $250^{*}$ & $500^{*}$ & $1000^{*}$ & P-value \\
\hline Liver & M & $3.50 \pm 0.11^{\mathrm{b}}$ & $2.92 \pm 0.21^{\mathrm{a}}$ & $2.88 \pm 0.05^{\mathrm{a}}$ & $2.79 \pm 0.04^{\mathrm{a}}$ & 0.04 \\
& F & $4.16 \pm 0.48^{\mathrm{b}}$ & $3.73 \pm 0.28^{\mathrm{a}}$ & $3.21 \pm 0.15^{\mathrm{a}}$ & $3.50 \pm 0.17^{\mathrm{a}}$ & 0.02 \\
Heart & $\mathrm{M}$ & $0.59 \pm 0.04^{\mathrm{b}}$ & $0.38 \pm 0.00^{\mathrm{a}}$ & $0.56 \pm 0.01^{\mathrm{b}}$ & $0.43 \pm 0.02^{\mathrm{a}}$ & 0.01 \\
& F & $0.59 \pm 0.02^{\mathrm{b}}$ & $0.49 \pm 0.07^{\mathrm{ab}}$ & $0.30 \pm 0.07^{\mathrm{a}}$ & $0.40 \pm 0.02^{\mathrm{a}}$ & 0.04 \\
Spleen & M & $0.25 \pm 0.02^{\mathrm{a}}$ & $0.28 \pm 0.01^{\mathrm{a}}$ & $0.25 \pm 0.00^{\mathrm{ab}}$ & $0.21 \pm 0.02^{\mathrm{b}}$ & 0.02 \\
& F & $0.32 \pm 0.02^{\mathrm{b}}$ & $0.23 \pm 0.01^{\mathrm{a}}$ & $0.18 \pm 0.01^{\mathrm{a}}$ & $0.23 \pm 0.02^{\mathrm{a}}$ & 0.01 \\
Lungs & $\mathrm{M}$ & $0.78 \pm 0.18^{\mathrm{c}}$ & $0.54 \pm 0.02^{\mathrm{b}}$ & $0.79 \pm 0.02^{\mathrm{c}}$ & $0.63 \pm 0.02^{\mathrm{a}}$ & 0.001 \\
& F & $1.06 \pm 0.25^{\mathrm{b}}$ & $0.95 \pm 0.00^{\mathrm{d}}$ & $0.85 \pm 0.00^{\mathrm{c}}$ & $0.74 \pm 0.00^{\mathrm{a}}$ & 0.001 \\
Kidney & $M$ & $0.49 \pm 0.16^{\mathrm{b}}$ & $0.32 \pm 0.00^{\mathrm{ab}}$ & $0.29 \pm 0.01^{\mathrm{a}}$ & $0.36 \pm 0.01^{\mathrm{c}}$ & 0.011 \\
& F & $0.48 \pm 0.01^{\mathrm{a}}$ & $0.42 \pm 0.01^{\mathrm{ab}}$ & $0.49 \pm 0.05^{\mathrm{a}}$ & $0.36 \pm 0.00^{\mathrm{b}}$ & 0.04
\end{tabular}

Values: mean \pm SEM, M=Male, F=Female, ${ }^{*} \mathrm{mg} / \mathrm{kg}$ BW

Table-5: Hematological values of control and rats treated withC. swynnertonii hexane extract measured during sub-acute toxicity

\begin{tabular}{|c|c|c|c|c|c|c|}
\hline \multicolumn{3}{|c|}{ Parameter Sex Control } & \multirow{2}{*}{$\frac{250^{*}}{59.91 \pm 3.02}$} & \multirow{2}{*}{$\frac{500^{*}}{52.22 \pm 0.24}$} & \multirow{3}{*}{$\begin{array}{l}1000^{*} \\
48.86 \pm 0.41 \\
48.33 \pm 0.57\end{array}$} & P-value \\
\hline $\mathrm{WBC}$ & $\mathrm{M}$ & $56.05 \pm 0.62$ & & & & 0.06 \\
\hline$\left(\mathrm{m} / \mathrm{mm}_{3}\right)$ & $\mathrm{F}$ & $58.43 \pm 0.54$ & $48.66 \pm 4 \cdot 71$ & $51.73 \pm 1.17$ & & 0.12 \\
\hline $\mathrm{RBC}$ & M & $6.83 \pm 0.67$ & $3.61 \pm 1.01$ & & & 0.08 \\
\hline$(\mathrm{m} / \mathrm{n}$ & $\mathrm{F}$ & $6.33 \pm 0.60$ & & & $4.36 \pm 0.01$ & 0.51 \\
\hline $\mathrm{MCV}$ & M & 66.1 & $58.65 \pm 2$ & & & 0.06 \\
\hline (fl) & $\mathrm{F}$ & $61.5 \pm 0.40^{\mathrm{b}}$ & $59.7 \pm 0.80^{a}$ & $60.2 \pm 1.00^{\mathrm{a}}$ & $61.25 \pm 0.36^{a}$ & 0.03 \\
\hline HCT(\%) & M & $37.2 \pm 2.70^{a}$ & $20.85 \pm 4.95^{b}$ & & & 0.04 \\
\hline & $\mathrm{F}$ & $38.9 \pm 3.90$ & & & & 0.70 \\
\hline $\mathrm{MCH}$ & M & 23.2 & & & $24 \cdot 7$ & 0.82 \\
\hline & $\mathrm{F}$ & $23.85 \pm 0.15$ & $21.8 \pm 0.80$ & $26.7 \pm 0.70$ & $27.24 \pm 0.37$ & 0.06 \\
\hline $\mathrm{HC}$ & M & & & & & 0.97 \\
\hline (g/u) & $\mathrm{F}$ & $38.9 \pm 0.10$ & $36.7 \pm 1.80$ & $44.4 \pm 0.40$ & $45.06 \pm 0.16$ & 0.05 \\
\hline $\mathrm{Hb}$ & M & $15.75 \pm 0.25$ & & & 35 & 0.23 \\
\hline (g/dl) & $\mathrm{F}$ & $16.65 \pm 0.05$ & $11.5 \pm 4.90$ & $14.45 \pm 0.65$ & $12.22 \pm 0.12$ & 0.63 \\
\hline MPV & M & $7.25 \pm 0.05$ & $7 \cdot 3 \pm 0.30$ & $14.45 \pm 0.05$ & $7 \cdot 3 \pm 0.10$ & 0.39 \\
\hline (fl) & $\mathrm{F}$ & $7 \cdot 5 \pm 0.00^{a}$ & $7 \cdot 3 \pm 0.00^{\mathrm{a}}$ & $14.45^{ \pm 0.05^{b}}$ & $7 \cdot 5 \pm 0.00^{\mathrm{a}}$ & 0.021 \\
\hline
\end{tabular}

Values: mean \pm SEM, M=Male, F=Female, ${ }^{*} \mathrm{mg} / \mathrm{kg}$ BW 
Table-6: Hematological values of control and rats treated with C.swynnertonii chloroform extract measured during sub-acute toxicity

\begin{tabular}{|c|c|c|c|c|c|c|}
\hline ra & & & $250^{*}$ & $500^{*}$ & $1000^{*}$ & \\
\hline $\begin{array}{l}J \mathrm{BC} \\
\left.\mathrm{n} / \mathrm{mm}_{3}\right)\end{array}$ & $\begin{array}{l}\mathrm{M} \\
\mathrm{F}\end{array}$ & $\begin{array}{l}56.05 \pm 0.62^{d} \\
58.43 \pm 0.54^{c}\end{array}$ & $\begin{array}{l}53.06 \pm 0.16^{c} \\
54 \pm 0.35^{b}\end{array}$ & $\begin{array}{l}51.22 \pm 0.24^{\mathrm{b}} \\
51.05 \pm 1.49^{\mathrm{ab}}\end{array}$ & $\begin{array}{l}47.61 \pm 0.61^{a} \\
47.58 \pm 0.82^{a}\end{array}$ & $\begin{array}{l}0.001 \\
0.001\end{array}$ \\
\hline $\begin{array}{l}\mathrm{BC} \\
\left.\mathrm{n} / \mathrm{mm}_{3}\right)\end{array}$ & $\begin{array}{l}\mathrm{M} \\
\mathrm{F}\end{array}$ & & & $\begin{array}{l}4.76 \pm 0.09^{b} \\
5.39 \pm 0.44^{c}\end{array}$ & & \\
\hline $\begin{array}{l}\text { ICV } \\
\text { l) }\end{array}$ & $\begin{array}{l}\mathrm{M} \\
\mathrm{F}\end{array}$ & & $\begin{array}{l}62.45 \pm 0.35^{b} \\
58.14 \pm 0.27^{a}\end{array}$ & & & 0.001 \\
\hline${ }^{H} C T$ & $\begin{array}{l}\mathrm{M} \\
\mathrm{F}\end{array}$ & & & & & .31 \\
\hline g) & $\begin{array}{l}\text { M } \\
F\end{array}$ & $\begin{array}{l}25.1 \pm 0.1^{\mathrm{b}} \\
23.85 \pm 0.15^{\mathrm{ab}}\end{array}$ & $\begin{array}{l}24.6 \\
21.9\end{array}$ & $\begin{array}{l}23.63 \pm 0.07^{\mathrm{a}} \\
21.9 \pm 1.30^{\mathrm{a}}\end{array}$ & $\begin{array}{l}0.06^{\mathrm{a}} \\
30^{\mathrm{b}}\end{array}$ & 0.04 \\
\hline $\begin{array}{l}\text { MCHC } \\
\mathrm{g} / \mathrm{dl})\end{array}$ & $\begin{array}{l}M \\
F\end{array}$ & & $\begin{array}{l}36.35 \pm 2.75 \\
38.6 \pm 0.30\end{array}$ & & & 0.13 \\
\hline $\begin{array}{l}\mathrm{Hb} \\
\mathrm{g} / \mathrm{dl})\end{array}$ & $\begin{array}{l}M \\
F\end{array}$ & & $\begin{array}{l}12.95 \pm 0.65^{b} \\
14.5 \pm 0.30^{c}\end{array}$ & $\begin{array}{l}11.45 \pm 0.05^{a} \\
13.4 \pm 0.30^{b}\end{array}$ & $\begin{array}{l}10.5 \pm 0.20^{a} \\
9.7 \pm 0.20^{a}\end{array}$ & $\begin{array}{l}0.002 \\
0.001\end{array}$ \\
\hline $\begin{array}{l}\text { IPV } \\
1)\end{array}$ & $\begin{array}{l}\mathrm{M} \\
\mathrm{F}\end{array}$ & $\begin{array}{l}7.25 \pm 0.05^{b} \\
7.5 \pm 0.00\end{array}$ & $\begin{array}{l}7.65 \pm 0.05^{a} \\
7.6 \pm 0.00\end{array}$ & $\begin{array}{l}7.65 \pm 0.05^{\mathrm{a}} \\
7.5 \pm 0.10\end{array}$ & $\begin{array}{l}7.55 \pm 0.05^{a} \\
7.35 \pm 0.15\end{array}$ & 0.01 \\
\hline
\end{tabular}

Table-7: Biochemical parameters of control and rats treated with

C. swynnertonii hexane extract measured during sub-acute toxicity

\begin{tabular}{llllllr}
\hline \multicolumn{2}{l}{ Parameter Sex Control } & $250^{*}$ & $500^{*}$ & $1000^{*}$ & \multicolumn{2}{l}{ P-value } \\
\hline ALT & M & $46.66 \pm 3.33$ & $45.00 \pm 1.67$ & $46.66 \pm 0.00$ & $46.66 \pm 3.33$ & 0.95 \\
(u/l) & F & $54.99 \pm 1.67$ & $54.99 \pm 8.33$ & $49.99 \pm 0.01$ & $69.99 \pm 0.00$ & 0.10 \\
AST & M & $88.32 \pm 8.33$ & $88.32 \pm 31.66$ & $119.99 \pm 0.00$ & $63.33 \pm 10.00$ & 0.28 \\
(u/l) & F & $84.99 \pm 1.67^{d}$ & $76.66 \pm 3.33^{c}$ & $53.33 \pm 3.33^{\mathrm{a}}$ & $66.67 \pm 0.01$ & 0.01 \\
ALP & M & $262.58 \pm 135.44$ & $253.686 \pm 3.37$ & $250.41 \pm 0.09$ & $210.188 \pm 0.12$ & 0.94 \\
(u/l) & F & $323.39 \pm 66.34$ & $187.95 \pm 96.74$ & $100.89 \pm 17.97$ & $69.99 \pm 0.00$ & 0.12 \\
Albumin & M & $3.94 \pm 0.05$ & $3.00 \pm 0.78$ & $3.40 \pm 0.00$ & $3.04 \pm 0.03$ & 0.40 \\
(g/dl) & F & $3.71 \pm 0.02$ & $4.15 \pm 0.60$ & $3.79 \pm 0.65$ & $2.61 \pm 0.01$ & 0.22 \\
Bilirubin & M & $1.24 \pm 0.32$ & $1.08 \pm 0.12$ & $0.97 \pm 0.01$ & $1.07 \pm 0.49$ & 0.93 \\
(mol/l) & F & $1.24 \pm 0.60$ & $0.79 \pm 0.77$ & $0.66 \pm 0.08$ & $0.62 \pm 0.00$ & 0.8 \\
T.protein & M & $7.16 \pm 0.11$ & $7.61 \pm 0.76$ & $8.74 \pm 0.00$ & $7.00 \pm 0.64$ & 0.20 \\
(g/dl) & F & $7.14 \pm 0.49$ & $6.52 \pm 0.44$ & $6.12 \pm 0.53$ & $6.91 \pm 0.01$ & 0.44 \\
Creatinine & M & $0.67 \pm 0.08$ & $0.67 \pm 0.08$ & $0.58 \pm 0.00$ & $0.62 \pm 0.04$ & 0.74 \\
& F & $0.54 \pm 0.04^{\mathrm{a}}$ & $0.49 \pm 0.05^{\mathrm{a}}$ & $0.54 \pm 0.04^{\mathrm{a}}$ & $0.33 \pm 0.00^{\mathrm{b}}$ & 0.05 \\
\hline
\end{tabular}

Table-8: Biochemical parameters of control and rats treated with C. swynnertonii chloroform extract measured during sub-acute toxicity

\begin{tabular}{|c|c|c|c|c|c|c|}
\hline \multicolumn{3}{|c|}{ Parameter Sex Control } & \multirow{2}{*}{$\frac{250^{*}}{54.99 \pm 8.33^{a}}$} & \multirow{2}{*}{$\frac{500^{*}}{82.82 \pm 0.51^{b}}$} & \multicolumn{2}{|c|}{ 1000* P-value } \\
\hline & $M$ & $46.66 \pm 3.33^{a}$ & & & $59.99 \pm 0.01^{a}$ & 0.018 \\
\hline 1/l) & & & & $58.33 \pm 1.67^{\mathrm{a}}$ & $68.33 \pm 1.67^{c}$ & 0.001 \\
\hline & & & & & & 0.54 \\
\hline & $\Gamma$ & & & $96.66 \pm 3$. & $0.50^{\mathrm{a}}$ & 0.001 \\
\hline & & & & & & 0.67 \\
\hline & & & & $152.02 \pm 11.06^{a}$ & 149.2 & .037 \\
\hline \multirow{2}{*}{$\begin{array}{l}\text { Albumin } \\
(\mathrm{g} / \mathrm{dl})\end{array}$} & $\mathrm{M}$ & & & & & 0.011 \\
\hline & $\mathrm{F}$ & & & & & 0.12 \\
\hline \multirow{2}{*}{$\begin{array}{l}\text { Bilirubin } \\
(\mathrm{mol} / \mathrm{l})\end{array}$} & M & & & & & 0.01 \\
\hline & $\mathrm{F}$ & & & & & 0.19 \\
\hline \multirow{2}{*}{$\begin{array}{l}\text { T.protein } \\
\text { (g/dl) }\end{array}$} & & & & & & 0.20 \\
\hline & & & $7.67 \pm c$ & & $8.12 \pm 0.22$ & 0.24 \\
\hline \multirow[t]{2}{*}{ Creatinine } & & & & & & 0.294 \\
\hline & $\mathrm{F}$ & $0.54 \pm 0.04^{\mathrm{b}}$ & $0.83 \pm 0.00^{a}$ & $0.85 \pm 0.00^{a}$ & $0.92 \pm 0.03^{a}$ & 0.002 \\
\hline
\end{tabular}

Values: mean \pm SEM, M=Male, F=Female, ${ }^{*} \mathrm{mg} / \mathrm{kg}$ BW

\section{Discussion:}

The acute toxicity was investigated in order to determine whether administration of a single high dose of C. swynnertonii hexane and chloroform extract brought any adverse effect on tested animals during the 14 days after the oral administration. In the present study, oral administration of $C$. swynnertonii hexane and chloroform in albino mice at 500, 1000 and 2000 $\mathrm{mg} / \mathrm{kg}$ for 14 days had no effects on mortality or any examined clinical signs of toxicity. No acute toxicity was found in mice treated with $C$. swynnertonii extracts, so the approximate lethal dose was determined to be higher than 2000 $\mathrm{mg} / \mathrm{kg}$.

The sub-acute toxicity study, which involved rats given $C$. swynnertonii hexane and chloroform extract at doses of 250, 500 and $1000 \mathrm{mg} / \mathrm{kg}$ body weight, generally elicited no clinical signs of toxicity, mortality or any behavioral changes. The results from this study indicated that $C$. swynnertonii hexane and chloroform extract induced a normal change in body weight and therefore it can be suggested that the tested extracts had no effects on the body weights of the rats.

Organ weight is an important index to detect whether the organ was exposed to the injury or not (Jothy et al., 2011). Findings from this study revealed that the observed significant decreased in the weight of the liver of rats treated with $C$. swynnertonii hexane extract was not corroborated by both the histological examination and other biochemical parameters of liver function and therefore indicating that the extract is virtually nontoxic. The significant decrease in liver, heart, spleen, lung, and kidney weight of rats treated with C. swynnertonii chloroform extract indicating that chloroform extract contains some toxic substances that affected the weight of internal organs of the rats. Blood is an important index of physiological status in both man and animals (Vaghasiya et al., 2011). In this study, the nonsignificant difference in WBC, RBC, $\mathrm{MCH}$, $\mathrm{MCHC}$ and $\mathrm{Hb}$ of the rats' treatment with $C$. swynnertonii hexane extract indicated that the extract may be nontoxic to the blood. Reductions in $\mathrm{RBC}, \mathrm{MCV}, \mathrm{MCH}$ and $\mathrm{Hb}$ of the rats treated with C. swynnertonii chloroform extract indicated that the extract interfered with the normal production of hemoglobin and its concentrations within red blood cells. Thus, it can be suggested that $C$. swynnertonii chloroform extract may possess the 
Figure-1(a\&b): Treatment effects on histological examinations of the main organs in the rats during subacute toxicity study. Representative photomicrographs from liver, kidney, spleen, lung and heart sections stained with hematoxylin and eosin $(\times 40)$, respective groups: (A) control group (B) treated group $(250 \mathrm{mg} / \mathrm{kg})(\mathrm{C})$ treated group $(500 \mathrm{mg} / \mathrm{kg})$ (D) treated group (1000mg/kg).

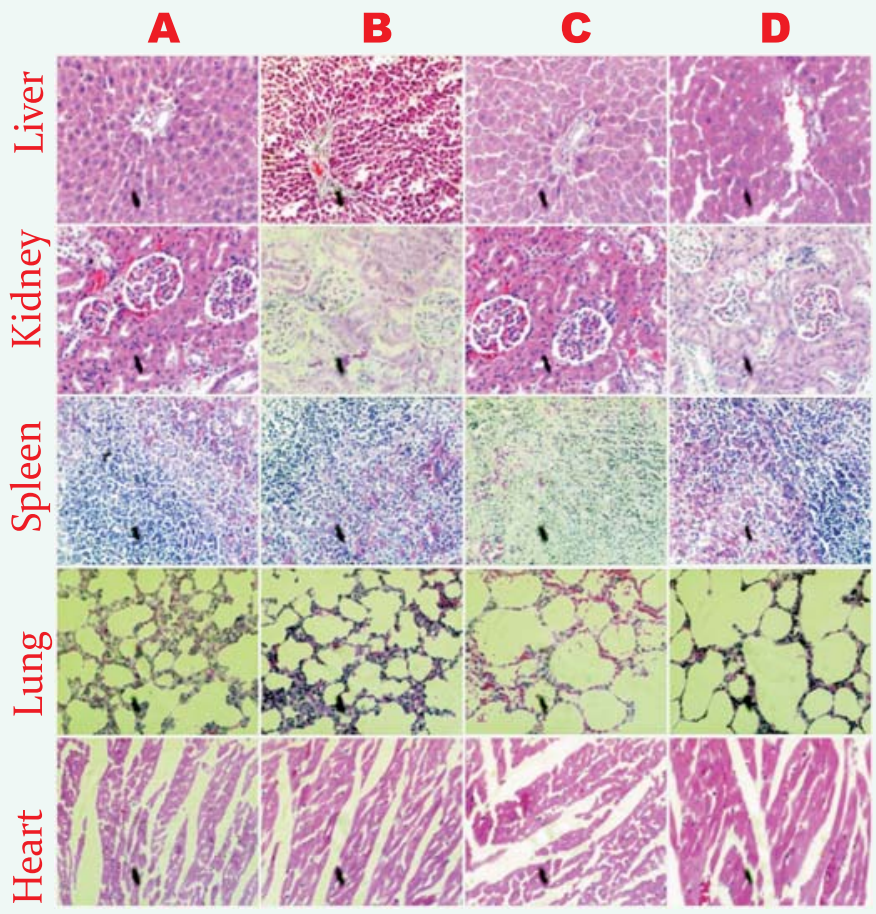

Figure-1a:Treatment- C. swynnertonii hexane extract

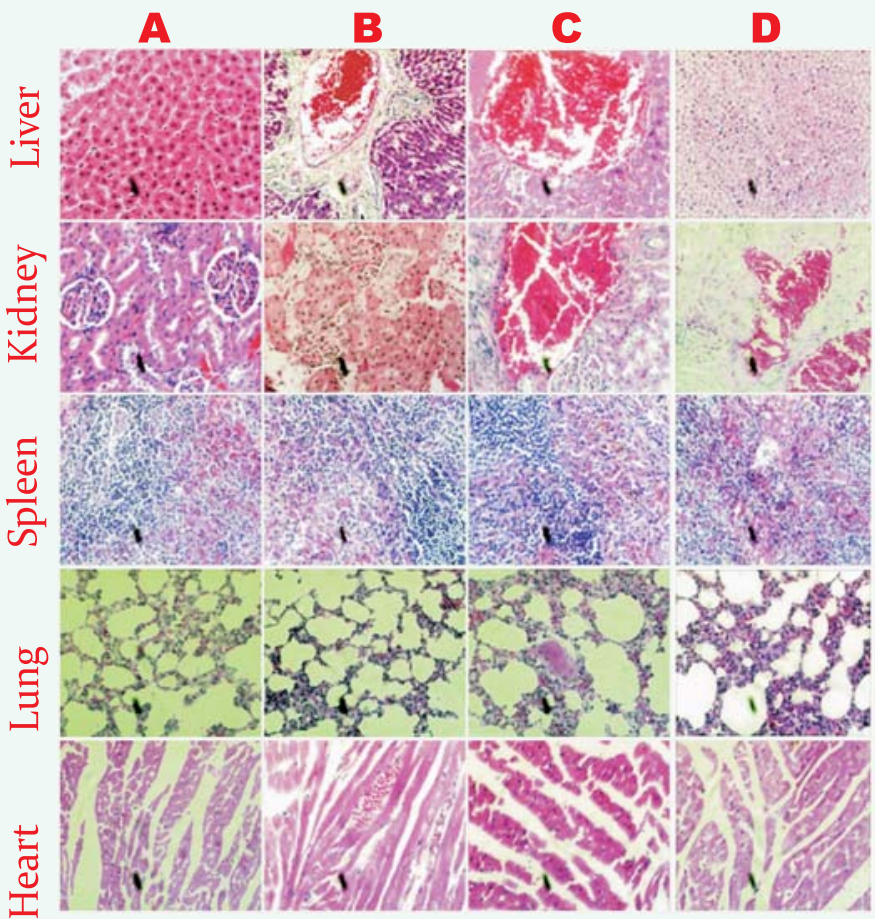

Figure-1b:Treatment- C. swynnertonii chloroform extract potential to induce anemia (Amna et al., 2013). The observed reduction in WBC in the rats treated with $C$. swynnertonii chloroform extract may suggest a decline in the function of the immune system. Evaluation of biochemical parameters may provide useful information regarding the overall health status and alteration in metabolic processes of the animals caused by ingestion of plant extracts (Tarkang et al., 2012). The liver and the kidneys are target organs for toxic chemicals due to their essential functions in biological detoxication and excretion processes (Bello et al., 2016). When the liver cell is damaged, a variety of enzymes normally located in the cytosol are released into the blood stream. The transaminases (AST and ALT) and ALP are well-known enzymes used as good indicators of liver function (Ismail et al., 2014). The kidneys excrete metabolic waste products and regulate the serum concentration of a variety of substances (Benouadah et al., 2016). Creatinine is an important biomarker of renal toxicity and increases the levels of these parameters indicates a marked renal damage (Suryavanshi et al., 2015). Results from this study showed that oral administration of $C$. swynnertonii hexane extract to albino rats revealed the insignif icant changes of most of the serum biochemical parameters which suggest the nontoxic nature of the extract. The observed significant increase in ALT, AST and creatinine for female; albumin and bilirubin for the male in the rats treated with $C$. swynnertonii chloroform extract indicated that the extract may induce liver damage probably by altered cell membrane permeability leading to the leakage of the enzymes from the tissues to the serum. The histopathological result of liver sections of rats treated with $C$. swynnertonii chloroform extract confirmed these effects indicating normal to severe congestion and the initial stage of necrosis. Regarding the kidney function, the significant increase in serum level of creatinine in the test groups treated with $C$. swynnertonii chloroform extract suggests possible renal damage. Histological aspects indicated a severe congestion and destruction of glomerular's shape in the kidney.

\section{Conclusion:}

The results from acute toxicity concluded that $\mathrm{LD}_{50}$ of $C$. swynnertonii hexane and chloroform extracts is above $2000 \mathrm{mg} / \mathrm{kg}$ body weight. Following its 28 -day repeated daily oral dose administration of $C$. swynnertonii hexane and chloroform extracts in the animals, it may be concluded that $C$. swynnertonii hexane extract does not elicit any treatment-related adverse effect at the investigated doses and thus may be classif ied to be virtually non-toxic. The observed some changes in the hematological, serum biochemical parameters with endorgan damage to the liver and kidney which lead to the alterations in the normal physiological functions of the animals, it can be concluded that the prolonged 
consumption of $C$. swynnertonii chloroform extract can cause some virtually toxic effect in the blood and also cause some damage to the internal organs. Therefore, caution and safety measures should be taken before oral ingestion of C. swynnertonii chloroform extract.

\section{Acknowledgements:}

This work is sponsored by Regional Universities FORUM for capacity building in agriculture. The authors wish to thank RUFORUM through RUFORUM CAA Project for financial support towards preparation of this work.

\section{References:}

Adam, M.E. \& Selim S.A. (2013): Antimicrobial activity of essential oil and methanol extract from Commiphora molmol (Engl.) resin. Int. J. Curr. Microbiol. App. Sci., 2(12):1-6.

Amna, O.F., Nooraain, H., Noriham, A., Azizah, A. \& Husna R.N. (2013): Acute and oral subacute toxicity study of ethanolic extract of Cosmos caudatus leaf in Sprague Dawley rats. Int. J. Bios. Biochem. Bioinform., 3(4):301-305.

Bello, I., Bakkouri, A.S, Tabana, Y.M. \& Al-hindi, B. (2016): Acute and Sub-Acute Toxicity Evaluation of the Methanolic Extract of Alstonia scholaris Stem Bark. Med.Sci., 4(1): 4 .

Benouadah, Z., Mahdeb, N., Bouzidi, A. (2016): Evaluation of Acute and Sub-Acute Toxicity of Alkaloids from Datura stramonium Sp. in Mice. Int. J. Pharmacog. Phytochem. Res., 8: 1759-1766.

Ismail, Z., Halim, S.Z., Abdullah, N.R., Afzan, A., Abdul Rashid, B.A. \& Jantan, I. (2014): Safety Evaluation of Oral Toxicity of Carica papaya Linn. leaves: A Subchronic Toxicity Study in Sprague Dawley Rats. Evi-Based Compl. Alt. Med., Article ID 741-470.

Jothy, L.S., Zakaria, Z., Chen. Y., Lau, Y.L., Yoga Latha, L. \& Sasidharan, S. (2011): Acute oral toxicity of methanolic seed extract of Cassia fistula in mice. Molecules. 16(6);5268-5282.
Kalala, W., Magadula, J., \& Mdegela, H. (2014): Evaluating Acaricidal Activity of Commiphora swynertonii ( Burrt .) bark Exudate against common Ticks in Tanzania. Int. J. Herb. Med., 2(4):19-25.

Kaoneka, B., Mollel, M. \& Lyatuu, F. (2007): Leaf essential oil composition and tick repellency activity of Commiphora swynnertonii Burtt. L. Biol.Res., 8:213-216.

Mkangara, M., Erasto, P. \& Chacha, M. (2014a): Acaricidal activity of Commiphora Swynnertonii (Burtt) stem bark extracts against adult Rhipicephalus Appendiculatus newman and Amblyomma Variegatum. Am. J. Res. Comm., 2(9):82-92.

Mkangara, M., Chacha, M. \& Kazyoba, P.E. (2014b): Antimicrobial and Cytotoxicity Efficacy of Commiphora swynnertonii (Burtt) Extracts. Int.J.Sci. Res., 3(7):1611-1615.

OECD/OCDE (2001): Acute oral toxicity- up-and down procedure. OECD Guidelines for testing of chemicals. No. 425. P. 1-26.

Sambuta, A.K. \& Masola, S.N. (2006): The efficacy of Commiphora swynnertonii extracts in the control of external parasites in livestock. Proc. Papers COSTECH, 42 pages.

Suryavanshi, S.A., Shinde-Kadam, K., Raina, P., Nimbargi, R., Pandit, V.A. \& Kaul-Ghankar, R. (2015): Evaluation of Acute and Sub-Acute Toxicity of a Standardized Polyherbal Formulation (HC9): An In Vivo Study. Int. J. Pharm. Pharmaceut. Sci., 7(11):110-117.

Tarkang, P.A., Agbor, G.A., Armelle, T.D., Yamthe, T.L.R., David, K. \& Ngadena, Y.S.M. (2012): Acute and Chronic Toxicity Studies of the aqueous and ethanol leaf extracts of Carica papaya Linn in Wistar rats. J. Nat. Prod., 2(5):617627.

Vaghasiya, Y., Shukla, V. \& Chanda, S. (2011): Acute Oral Toxicity Study of Pluchea arguta Boiss Extract in mice. J. Pharmacol. Toxicol., 6(2), 113-23. 